Scientific Journal of Silesian University of Technology. Series Transport Zeszyty Naukowe Politechniki Śląskiej. Seria Transport

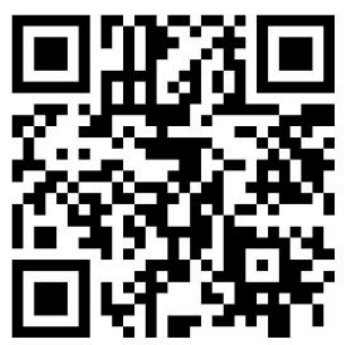

Volume 112

2021

p-ISSN: 0209-3324

e-ISSN: 2450-1549

DOI: https://doi.org/10.20858/sjsutst.2021.112.10

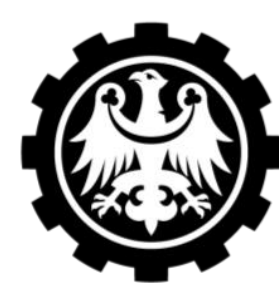

Silesian

University of Technology

Journal homepage: http://sjsutst.polsl.pl

Article citation information:

Labisz, K. Reflectivity of anodised Al-Si alloy surface of belt pulleys used in combustion engines. Scientific Journal of Silesian University of Technology. Series Transport. 2021, 112, 125-133. ISSN: 0209-3324. DOI: https://doi.org/10.20858/sjsutst.2021.112.7.10

Krzysztof LABISZ ${ }^{1}$

\title{
REFLECTIVITY OF ANODISED AL-SI ALLOY SURFACE OF BELT PULLEYS USED IN COMBUSTION ENGINES
}

Summary. The recent trend of using aluminium alloys instead of steel has reached the transportation industry, where increasingly, more parts are made of aluminium. An example is the belt pulley, applied for combustion engines for energy transmission. This part should be strong, durable, and lightweight. Aluminium-silicon alloys are a good choice, moreover, even when the surface is anodised, also because of their moderate inertia control and excellent wear characteristic during mechanical operations. Since aluminium is lightweight yet mechanically durable and anodised, it is an ideal belt pulley to use, especially in high-temperature operations. However, the main question is what type of $\mathrm{Al}-\mathrm{Si}$ alloy, casting method and anodisation method should be used in terms of energy adsorption, having long-term properties for a lifetime, has to be applied. For this reason, this paper presents the influence of the chemical composition, casting method and anodising parameters on the structure and thickness of the anodic layer produced on aluminium alloys, as well as on the albedo value as an ability to reflect or absorb light. The aluminium alloys, AlSi12Cu1 and AlSi9Cu3, were used as research materials, obtained using different casting methods. The goal of this work was to determine the optimal combination of the anodisation conditions and materials for maximising the reflectivity factor of the surface, as a very important factor, determining the energy amount absorbed by an anodised surface. For further improvement of these surface properties as well as for enhancement of

\footnotetext{
${ }^{1}$ Faculty of Transport and Aviation Engineering, The Silesian University of Technology, Krasińskiego 8 Street, 40-019 Katowice, Poland. Email: krzysztof.labisz@polsl.pl. ORCID: https://orcid.org/0000-0002-4613-830X
} 
the properties and strengthen the material produced with different aluminium alloys production methods, different alloying additives were added. In addition, the mechanical properties of the surface layer were measured, where a remarkable hardness increase was obtained, and the best combination in form of AlSi12Cul high pressure cast was found with the highest albedo factor among all tested surface variants.

Keywords: aluminium, reflectivity, adonisation, surface treatment, sand cast, high pressure cast, albedo

\section{INTRODUCTION}

In recent years, a continuous increase in the use of aluminium alloys across industries has been observed. Protective and decorative anodic coatings are applied to aluminium household goods, electronic components, parts of musical instruments, garden furniture, tourist and sports equipment, automotive accessories and aluminium joinery elements. Anodised aluminium wires are used as conductors in electrical installations. Oxide coatings are produced on aluminium foil intended for electrodes in capacitors. Hard anodic coatings are used in the aviation and transportation industries, where the effect on environmental pollutions is increasingly discussed [1-3].

Anodic oxide coatings permanently bonded to the aluminium substrate are corrosion resistant [4]. Corrosion resistance can be reduced by pores in the coating or by the presence of harmful alloying elements and impurities, especially copper. The intermetallic phases of copper with aluminium dissolve during anodising, which reduces the hardness and thickness of the coatings, increasing the porosity. During the formation of aluminium oxide, there is a slight increase in the mass of the workpiece and its volume. The oxide layer is very firmly attached to the substrate. Dissolution of the oxide layer is possible only in alkaline or acidic solutions with a $\mathrm{pH}$ greater than 8.8 or less than 4.0 [5].

A very important issue concerning the surface properties, beside the mechanical properties is the reflectivity and albedo. The albedo of an object or surface (Figure 1) is a measure of the percentage of light reflected from it for a certain incident light amount. A perfectly-reflecting mirror has an albedo of $100 \%(\mathrm{~A}=1.0)$ so that if a $100 \mathrm{~W}$ of visible light energy fall on its surface, a 100 watts will be reflected. The most perfect black surface, on the other hand, has an albedo of $0 \%(\mathrm{~A}=0)$ and will reflect no visible light energy at all. Instead, it absorbs $100 \%$ of the light energy, so if you want to figure out how hot a surface will get in direct sunlight, the amount of absorbed light energy is just $\mathrm{E}=100 \%$ - Reflected, or in terms of $\mathrm{A}$, we have $\mathrm{E}=$ Incident Energy x (1-A) [6, 7].

Albedo currently plays a very important role in world climate discussions, namely as the world warms up the Earth's albedo shifts. Albedo has also an influence on the lifetime of engineering materials, especially on surfaces and layer produced on such working elements. The amount of ice covering the planet is dropping because of increased temperatures from global warming. This causes a decrease in the area of white surfaces, leading to less energy to be reflected and more to be absorbed. This process warms the Earth even more. Therefore, this study aims to investigate the albedo value based on the microstructure and thickness of coatings produced on cast aluminium alloys during the anodisation process and evaluate the effect of electrolyte and alloy casting method on the anodic layer reflectivity and their working durability or damaging [8] to ensure long working time. 


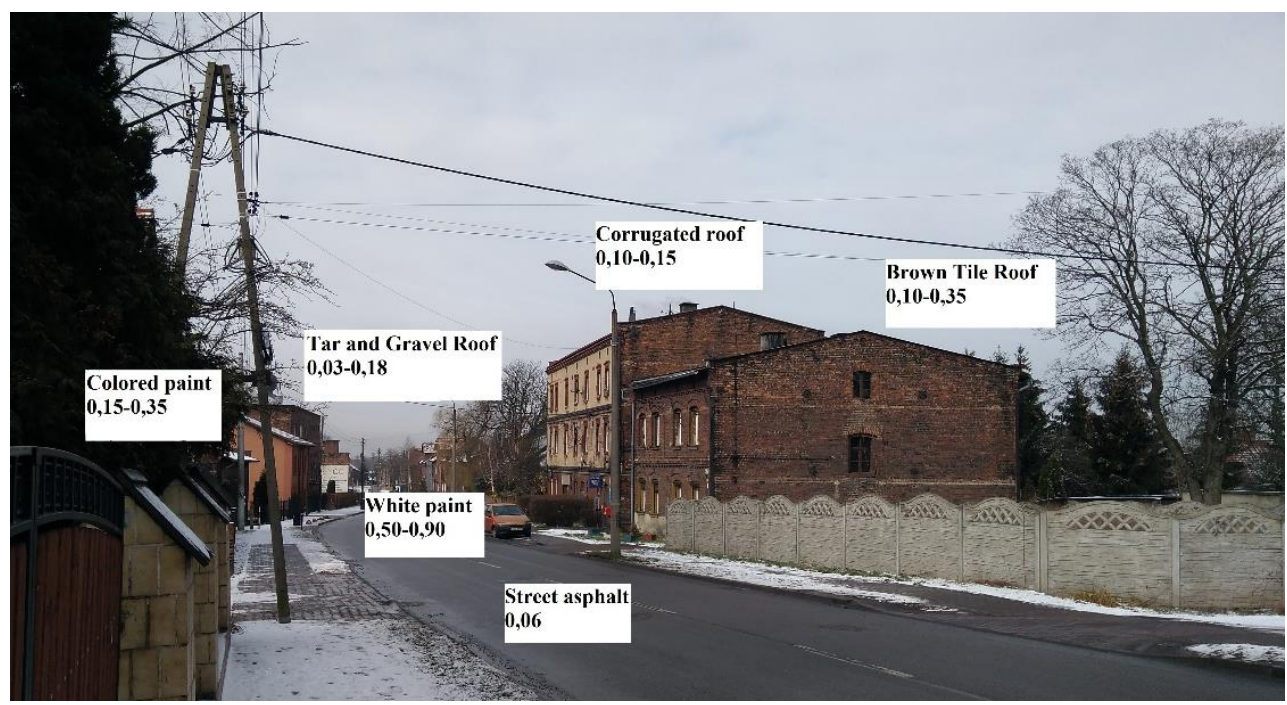

Fig. 1. Albedos of different surfaces

\section{INVESTIGATION PROCEDURE}

The tests were performed on samples of AlSi12Cu1 and AlSi9Cu3 alloys, used for pulleys production for combustion engines (Figure 2). The Al-casting was carried out using the high pressure die casting and sand casting methods applied for both the AlSi12Cu1 and AlSi9Cu3 alloys [9]. The chemical composition of the alloys is given in Table 1. The technological parameters of the anodising process are presented in Table 2. For anodising of the aluminium alloys $4 \% \mathrm{H}_{2} \mathrm{SO}_{4}$, the electrolyte in mass was applied.

Tab. 1

Chemical composition of AlSi12Cu1 and AlSi9Cu3 alloys

\begin{tabular}{|l|l|l|l|l|l|l|l|}
\hline \multirow{2}{*}{ Alloy } & \multicolumn{7}{|c|}{ Elements mass concentration, \% } \\
\cline { 2 - 8 } & $\mathrm{Si}$ & $\mathrm{Mg}$ & $\mathrm{Cu}$ & $\mathrm{Mn}$ & $\mathrm{Fe}$ & $\mathrm{Zn}$ & $\mathrm{Al}$ \\
\hline AlSi12Cu11 & 12.5 & 0.05 & 0.05 & 0.5 & 0.6 & 0.1 & balance \\
\hline AlSi9Cu3 & 9.5 & 1.5 & 3.0 & 0.5 & 0.9 & 0.5 & balance \\
\hline
\end{tabular}

Tab. 2

Anodising parameters used for treatment

\begin{tabular}{|l|l|}
\hline \multicolumn{1}{|c|}{ Parameter } & \multicolumn{1}{|c|}{ Value } \\
\hline Electrolyte, $[\mathrm{g} / \mathrm{l}]$ & $\mathrm{H}_{2} \mathrm{SO}_{4}$ with concentration of $295 \div 315$ \\
\hline Temperature, ${ }^{\circ} \mathrm{C}$ & $-4 \div 2$ \\
\hline \multirow{2}{*}{ Pulse current, $\left[\mathrm{A} / \mathrm{dm}^{2}\right]$} & 2 during $0.25 \mathrm{~s}$, \\
& 1 during $0.1 \mathrm{~s}$ \\
\hline $\mathrm{Al}$ ions concentration, $[\mathrm{g} / \mathrm{l}]$ & $6 \div 9$ \\
\hline
\end{tabular}




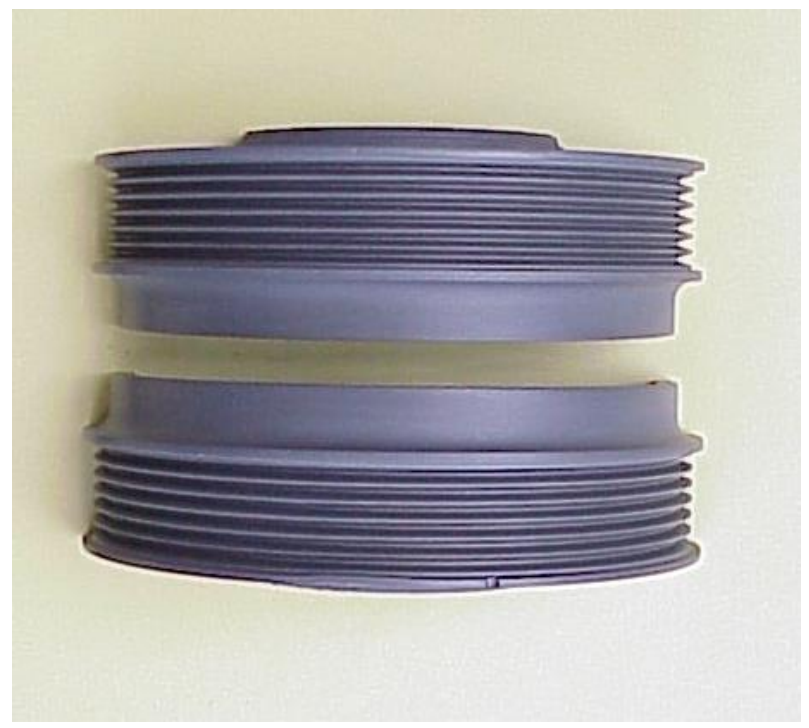

Fig. 2. Anodised Al-Si belt pulleys used in combustion engines

The metallographic tests were carried out on the OLYMPUS BX60M light microscope equipped with the OLYMPUS DP10 camera. The photos were processed on a PC using the OLYMPUS image analysis program.

Abrasive wear test was performed using the ABR-8251 supplied by TCD Teknologi ApS. The tests were carried out following the specifications and requirements of the ISO 8251 standard. A load of $4.9 \mathrm{~N}$ was used for the test, with a slip speed of 40 cycles/min. The test area is $12 \times 30 \mathrm{~mm}$.

To calculate albedo (1), (Table 1) it is necessary to measure with a light meter the amount of reflected light in lux, and the amount of light that is falling on the surface in lux according to the relationship below:

$$
\text { albedo [\%] = reflected light [lux]/direct light [lux] }
$$

If 10,000 lux falls on a surface and 6,000 lux is reflected, the albedo is 0.6 or $60 \%$. This is about the same as a sheet of ordinary white laser printer paper. Fresh snow has an albedo of $80 \%$, while fresh asphalt has an albedo of $10 \%$ or 0.1 .

Tab. 3

Albedo values for chosen objects

\begin{tabular}{|l|c|c|c|}
\hline Surface & Direct(lux) & Reflected(lux) & Albedo \\
\hline Street Asphalt (greyish) & 257,000 & 16,100 & 0.06 \\
\hline Grass lawn in shade & 16,600 & 431 & 0.03 \\
\hline White laser printing paper & 11,350 & 7,000 & 0.62 \\
\hline
\end{tabular}




\section{INVESTIGATION RESULTS}

As a result of an abrasive wear test, anodisation was found to reduce abrasive wear. The best wear resistance is achieved when the anode layer thickness is high (approx. $48 \mu \mathrm{m}$ ). Partial removal of the coating was observed for all castings made in the high pressure die casting method, where the coating thickness is lower (approx. $10 \mu \mathrm{m}$ ).

The results in Figure 3 show that anodised samples of sand cast AlSi9Cu3 alloy have half the mass loss than non-anodised ones. In the remaining cases, there is a reduction in mass loss from 30 to $47 \%$.

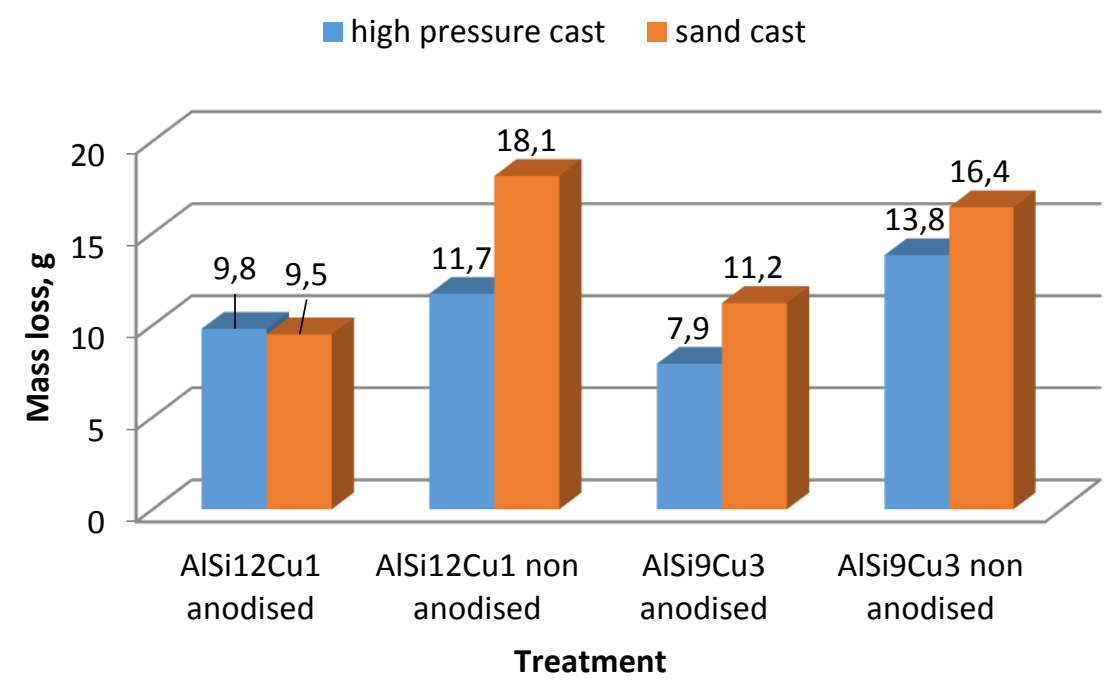

Fig. 3. Comparison of abrasion of pressure castings

The AlSi12Cu1 alloy samples show greater weight loss because the test site is close to the electrode attachment (the layer is probably thinner at this point).

Another variable that can influence the abrasive wear test results is the surface roughness (Table 4). Based on the obtained results, it was found that the higher roughness, which is characteristic of sand castings, has a positive effect on the abrasive wear test results.

As a result of the metallographic tests (Figures 4 - 7), it was found that the anodised layer produced on pressure and sand castings for both alloys does not show any gaps, which prevents the appearance of pitting, and the silicon precipitates contained in it (in the shape of needles) increase abrasion resistance.

Based on the measurements of the anodised layer thickness presented in Figure 8, it was found that for both alloys, the thickness of the anodised layer produced is greater in the case of sand casting and lower for pressure casting with the same anodising parameters.

The measured reflectivity values (Figure 9) ranges from 243 for high pressure AlSi9Cu3 cast to even 312 for the AlSi9Cu3 sand cast alloy, which provides the albedo value of 0.800 , thus, seems to be the best solutions in terms of choice for a high reflectivity surface, which can be applied for the treatment of constructional elements. The difference in reflectivity reaches even $28 \%$, as they are an important factor in the anodising treatment of aluminium alloys. 


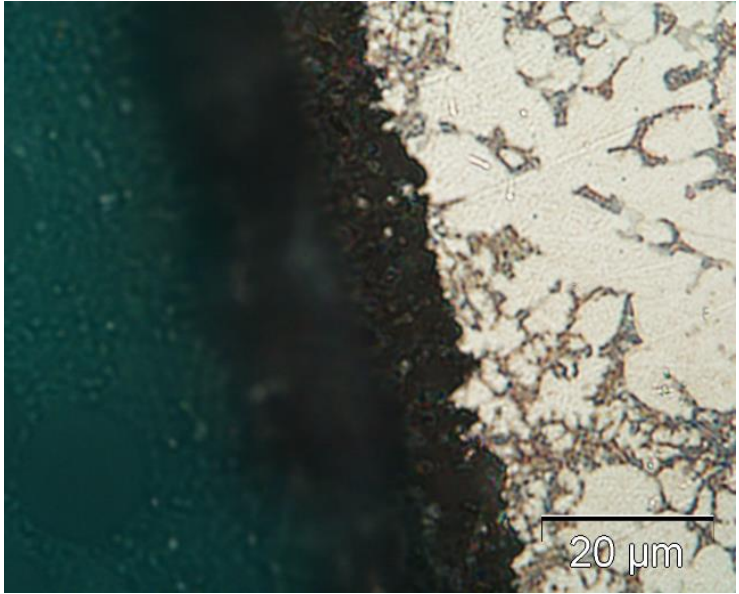

Fig. 4. Anodic layer produced on the AlSi9Cu3 alloy, high pressure cast

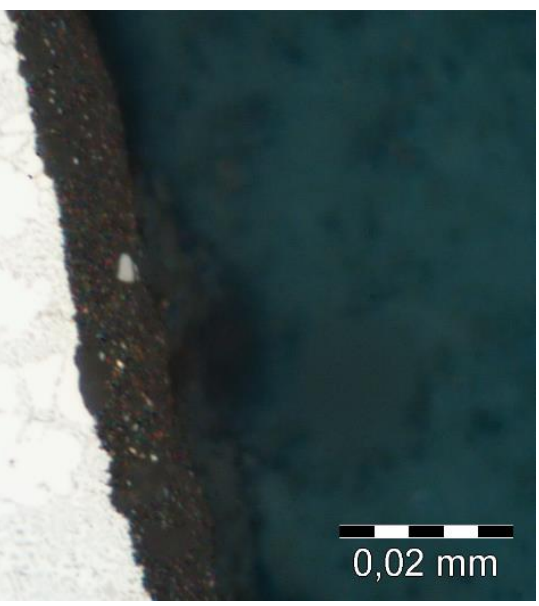

Fig. 6. Anodic layer produced on the AlSi12Cu1 alloy, high pressure cast

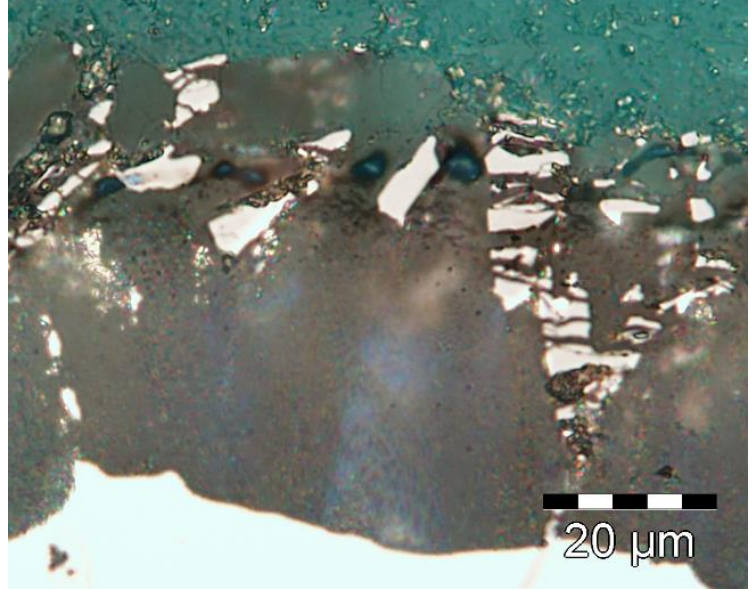

Fig. 5. Anodic layer produced on the AlSi9Cu3 alloy, sand cast

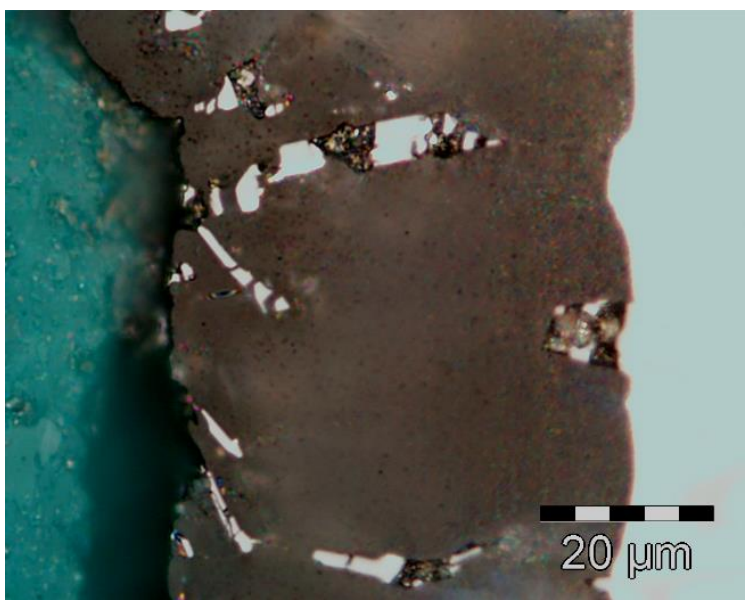

Fig. 7. Anodic layer produced on the AlSi12Cu1 alloy, sand cast

Tab. 4.

Roughness measured during the abrasive wear test

\begin{tabular}{|l|c|c|c|c|}
\hline \multirow{2}{*}{ Alloy } & \multicolumn{4}{|c|}{ Roughness, $\mathrm{R}_{\mathrm{a}} \mu \mathrm{m}$} \\
\cline { 2 - 5 } & \multicolumn{2}{|c|}{ Sand cast } & \multicolumn{2}{c|}{ High pressure cast } \\
\cline { 2 - 5 } & Non-anodised & Anodised & Non-anodised & Anodised \\
\hline AlSi9Cu3 & 0.38 & 3.26 & 0.28 & 1.93 \\
\hline AlSi12Cu1 & 0.35 & 1.84 & 0.24 & 1.52 \\
\hline
\end{tabular}




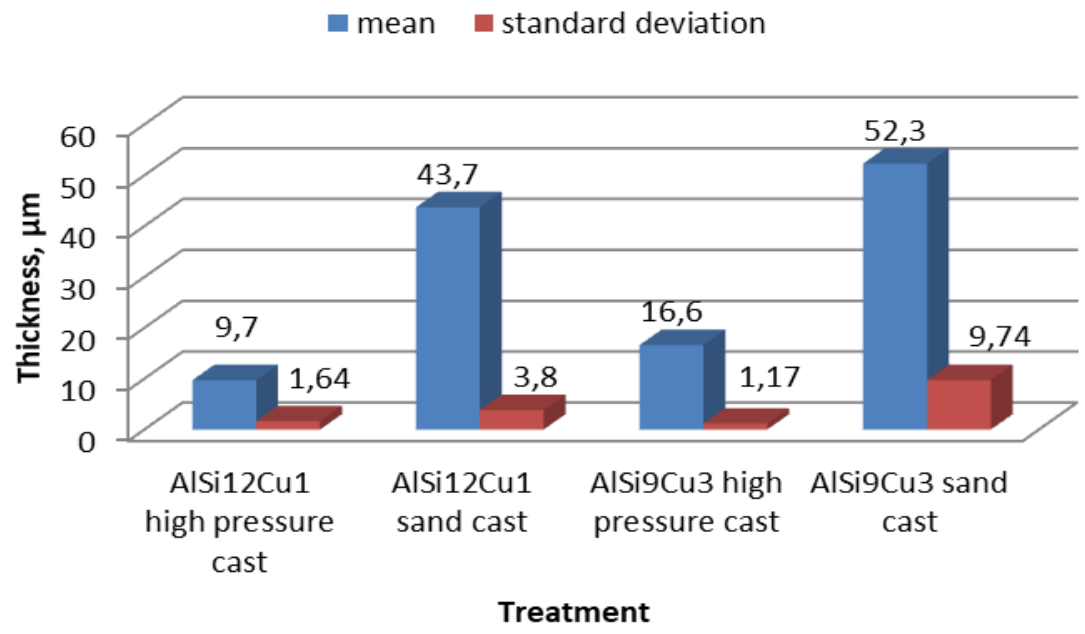

Fig. 8. Comparison of anodic layer thickness

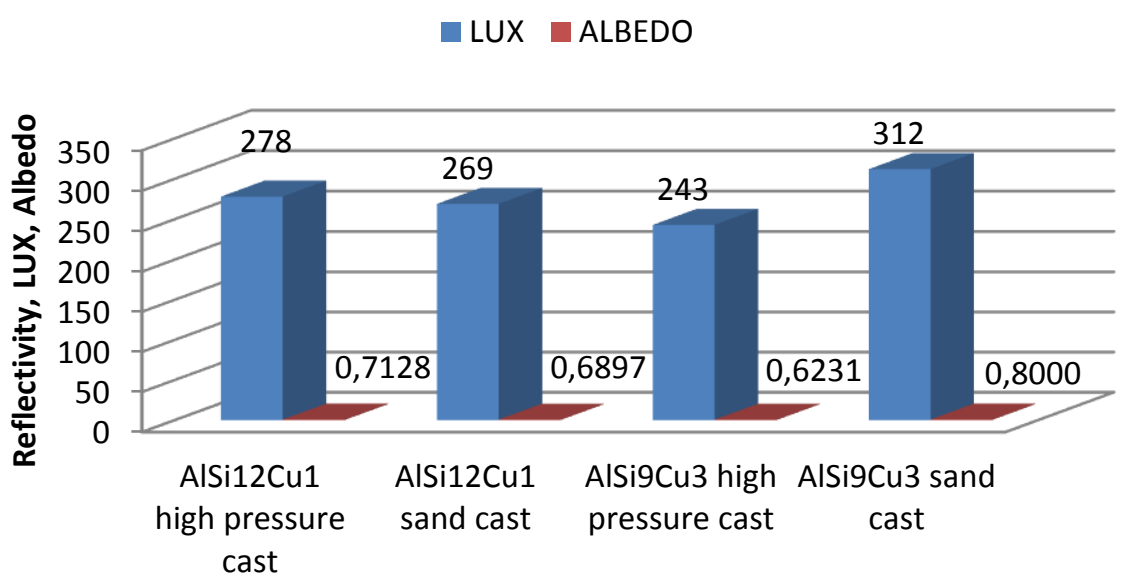

Treatment

Fig. 9. Reflectivity and albedo of the produced anodic layers

\section{CONCLUSIONS}

Proper anodisation method, as well as well-selected Al-Si alloys produced by casting, were determined in this paper in terms of the adsorption possibility of electromagnetic radiation. The reflectivity/albedo issue is very important for the proper working of car engine elements, especially in this case, of belt pulleys made of aluminium -silicon alloys. In general, high albedo value makes it possible to adsorb a relatively low amount of electromagnetic energy, thus, remarkably increase the durability and working time of anodised light materials used in the transportation industry.

During performing of this particular test, the following findings were determined: 
The test results given in Table 3 determined which of the tested alloys in combination with the appropriate production method (sand or pressure casting) has the highest abrasion resistance. The best results should be achieved with a combination of AlSi9Cu3 alloy with sand casting and AlSi12Cu1 alloy cast in die casting. Sand cast AlSi12Cu1 and die-cast AlSi9Cu3 have the lowest wear resistance.

The test results presented in the table show that anodised alloys, both AlSi9Cu3 and AlSi12, observed a lower weight loss compared to non-anodised alloys. It can be seen that the casting method also affects the wear resistance; sand cast alloys show a lower weight loss during the test carried out, therefore, they show higher abrasion resistance. Finally, the reflectivity value investigation, as an important factor for long time usage of parts has lead to the conclusion that the optimal combination for high reflectivity equal 312 lux was provided by the sand cast AlSi9Cu3 alloy with an albedo value of 0.8 , which can be partially associated with a relatively high surface roughness. The difference in reflectivity reaches $28 \%$ and is recognised as very important for the determination of proper anodising treatment of aluminium alloys in terms of environmental issues.

\section{References}

1. Nickel Daniela, Dagmar Dietrich, Roy Morgenstern, Ingolf Scharf, Harry Podlesak, Thomas Lampke1. 2016. "Anodisation of Aluminium Alloys by Micro-Capillary Technique as a Tool for Reliable, Cost-Efficient, and Quick Process Parameter Determination". Advances in Materials Science and Engineering Article ID 1374897: 1-12. DOI: http://dx.doi.org/10.1155/2016/1374897.

2. University of Calgary. „Energy education”. Available at: https://energyeducation.ca/encyclopedia/Albedo.

3. HyperPhysics. "Albedo of the Earth". Available at: http://hyperphysics.phyastr.gsu.edu/hbase/phyopt/albedo.html.

4. Gombar M., L. Sobotova, M. Badida, J. Kmec. 2014. "The comparison of possibilities at using of different electrolytes in the process of anodizing aluminium". Metalurgija 53(1): 47-50.

5. Curioni Michele, Tito Gionfini, Antonello Vicenzo, P. Skeldon, G. E. Thompson. 2013. "Optimization of anodizing cycles for enhanced performance". Surface and Interface Analysis 45(10): 1485-1489.

6. Yılmaza Demet, Ayşe Bayrakçeken, Yurtcanbc Tuba, Öznülüer Özercd, Fulya Memioğlub. 2021. "Albedo parameters and effective atomic numbers of PEDOT/Carbon black composites". Radiation Physics and Chemistry 182: 109378.

7. Jiang Tao, Chong Ji, Xin Wang, Ying Liu, Fuyin Gao, Yuxiang Sun, Kun Zhang, Lei Meng. 2021. "Experimental investigation on the damage effect of 6063-T5 aluminum alloy circular tubes subjected to blast after exposure to fire". Thin-Walled Structures 159: 107290.

8. Ahmetab Turşucu. 2021. "Albedo factor determination of some selected $3 \mathrm{~d}$ alloy samples". Applied Radiation and Isotopes 169: 109505.

9. Petrič M., J. Medved, P. Mrvar. 2011. "Effect of grain refinement and modification of eutectic phase on shrinkage of AlSi9Cu3 alloy". Metalurgija 50(2): 127-131. 
Received 05.04.2021; accepted in revised form 29.06.2021

$$
\text { (c) (i) }
$$

Scientific Journal of Silesian University of Technology. Series Transport is licensed under a Creative Commons Attribution 4.0 International License 